\title{
Can Foot Length be used as a Tool for Sex and Stature Determination among People Sample from Upper Egypt?
}

\author{
Morid Malak Hanna, Ghada Attia Eshak, and Eman Sameh Mohamed \\ Mostafa ${ }^{2}$
}

\footnotetext{
${ }^{1}$ Forensic Medicine and Clinical Toxicology Department

${ }^{2}$ Public health and Preventive Medicine Department
}

Faculty of Medicine, Minia University, Minia, Egypt

\begin{abstract}
Sex and stature identification from different parts of the body help in solving crime mysteries related to human identity. Estimation of stature becomes equally important along with other parameters like age and sex. The aim of this study was to determine whether foot length can be used in accurate sex and stature identification among people sample from Upper Egypt or not. The study was conducted on one hundred and twenty healthy Egyptian subjects from Minia city; 67 males with age ranged from 22- 40 years and 53 females with age ranged from 20- 38 years. Foot length and stature were accurately measured for each case by right angle triangle and weight and height scales indicator (health care provider). The collected data were statistically analyzed. The results showed that males had significantly greater mean value for foot length than females. Correct sex can be predicted from foot length with $90 \%$ accuracy. For all subjects; foot length showed strong positive correlation coefficients with stature. Males had slightly higher but moderate correlation coefficients than females. A regression formula was designed to calculate stature for Egyptians. It was concluded that foot length could be relied on to determine sex and stature accurately among Egyptians.
\end{abstract}

Keywords Foot length, stature, sex determination, Egyptians

\section{Introduction}

$\mathrm{F}$ orensic anthropology deals with identification of unrecognized human by determination of age, sex, race and stature. Stature or body height is one of the primary and useful tools used in personal identification. Estimation of stature from various body parts like extremities is well documented (Ozaslan et al., 2006). Stature and sex identification from different parts of the body help in solving crime mysteries related to human identity (Oberoi et al., 2005). Stature estimation from dismembered body parts can be done based on the ratio of the body part concerned, in relation to the entire body. The relationship between humerus, radius, ulna, femur, tibia, fibula and clavicle with the stature has been topics of research interest for decades (Pillay, 2004).

The Mathematical method was introduced and could determine stature from just one or a few pieces of bone. Commonly used bones presenting high accuracy in stature determination by this method is the long bones found in the upper and lower extremities (Chibba and Bidmos, 2007).
When the body has been mutilated, it is common to have the extremities or head amputated from the trunk. An estimate must then be made on the known relationship of the remains to stature. The introduction of regression formulae developed in the modern populations enhanced the accuracy of stature estimation (Chiba and Terazawa, 1998). It is known that body segments exhibit consistent ratio among themselves and relative to the total body stature. The ratios between body segments are age, sex, and race dependent. However, a number of common diseases or deformities of the vertebral column make it difficult to accurately measure standing stature in many patients (Auyeung et al., 2009).

Morphology of human feet is greatly influenced by the combined effects of heredity and living style of man that determines the size and shape of the feet or footprints and thereby makes them unique data to establish human identity (Rao and Kotian, 1990). Foot or shoe prints, if present at the scene of crime, may provide clue regarding the stature and sex of the person, which may help in establishing the 
partial identity of the suspect. Moreover, in aircraft accidents; feet are recovered more intact than other parts of the body, as they are often shoe clad. Hence, feet can be excellent clue regarding personal identity (Rao and Kotian, 1990; Oberoi et al., 2005). Foot length was sexually dimorphic in Turkish and Native North and Central Americans (Daniel et al., 2005), in Austrians and Canadians (Voracek et al., 2007), in Nigerians (Danborno and Elukpo, 2008) and in Chinese population (Hong et al., 2011). So the aim of this study was to determine whether foot length can help in accurate sex and stature identification among people sample from Upper Egypt or not.

\section{Subjects and Methods}

The study was carried out on one hundred and twenty subjects, 67 males with age ranged from 22- 40 years, and 53 females from 20-38 years. Subjects were taken by simple random sample method from Minia city. An informed verbal consent was taken from each participant after explaining the aim and methods of this work. All procedures were conducted in accordance with a standardized human subject's protocol that was approved by the Ethics Committee of Faculty of medicine, Minia University.

Healthy subjects without any physical abnormalities, developmental disorders or clinical features suggesting endocrinal or metabolic disease were included in the study.

Right foot length and stature for each person were measured according to Robbins, (1986) as the right foot was the dominant foot in the majority of them. Maximum foot length was measured as a straight line (distance) between the highest point of the first or the second toe (whichever was higher) and the lowest point on the margin of the heel that rested on hard straight surface. The measurement was taken by right angle triangle, its right side graduated up to $31 \mathrm{~cm}$ (figure1).

Stature (the height of a person in the upright posture) of each person was measured as a vertical distance from the bare foot to the vertex using weight and height scales indicator (model: health care provider). The subject was asked to stand straight with bare feet parallel and contact to each other, extended arms with hands directed medially and the head in the Frankfurt plane with eye looking forward. The head piece descended down to contact the vertex in the midsagittal plane (figure 2). The measuring unit for both foot length and stature was centimeters.

\section{Statistical analysis}

Data entry and analysis were done with Statistical Package for Social Sciences (SPSS) version 19. Graphics were done using Excel. Quantitative data were presented by mean \pm standard deviation, while qualitative data were presented by frequency distribution. Karl Pearson's Correlation coefficient (r) and 2 tailed Students't test were used. Linear regression equations were derived to determine the stature from foot length. Receiver Operating Characteristic (ROC) Curve was used to determine the cutoff point accuracy of foot length for sex discrimination. The probability of less than 0.05 was used as a cut off point for all significant tests.

\section{Results}

Results showed that the male subjects constituted $56 \%$ with mean age $27.61 \pm 7.35$ years, and females constituted $44 \%$ with mean age $24.19 \pm 6.85$ years (figure 3).

Table (1) shows means, standard deviations, minimum and maximum values of foot length and stature among males and females. Highly significant differences in both foot length and stature were found between males and females $(p=0.0001)$. Table (2) represents the mean \pm standard deviation of foot length and stature of the all subjects (males plus females).

By applying Receiver Operating Characteristic (ROC) curve; the cut off value of foot length was 23.95. So, all foot lengths equal to or less than 23.95 were presumed to be belonging to females, while foot length greater than 23.95 were males. The accuracy of predicting sex by this method was $90 \%$ with $96 \%$ sensitivity and $81 \%$ specificity (table 3 , figure 4).

Using Karl Pearson's correlation coefficients; results showed strong positive correlation between foot length and stature for all subjects $(\mathrm{r}=0.8, \mathrm{P}=0.0001)[\mathrm{r}$ : 0.00 to 0.24 (weak or no correlation), 0.25 to 0.49 (fair correlation), 0.50 to 0.74 (moderate correlation), $0.75+$ (strong correlation)] (figure 5). Males tend to have a slightly higher moderate positive correlation than females (table 4).

The regression equations for estimation of stature in $\mathrm{cm}$ from foot length in adult males and females have been calculated by regression analysis of the data, and the values of constants 'a' and ' $b$ ', where ' $a$ ' is the regression coefficient of the dependent variable which was the stature, and ' $b$ ' is the regression coefficient of the independent variable which was foot length. Hence,

Stature $=a+b x$ where, ' $x$ ' is foot length measurement. Regression equations for estimation of stature in adult males, females and all subjects are presented in table (5). The standard error of estimate (SEE) was calculated separately for each regression formulae for estimation of stature. A low value is indicative of the greater reliability of prediction from a particular measurement, and the higher value of SEE denotes less reliability of prediction.

A comparison between actual stature and estimated stature from foot length measurement using regression analysis is illustrated in table (6). Minimum, maximum, and mean values of the measurements were substituted in their respective regression equations, and estimated stature was calculated. It is clear that in both males and females; minimal estimated stature is greater than the actual minimal stature which is 155.9 and $153.5 \mathrm{~cm}$ respectively. On the other hand, the value of the maximal estimated stature is lower than the actual stature in both males and females (i.e. $181.5 \mathrm{~cm}$ and $173.6 \mathrm{~cm}$ respectively). However, the mean value estimates (mean estimated stature) for male and female are close to the actual stature. This is due to the fact 
that the regression equations are calculated from measures of central tendency.

Table (1): Mean, standard deviations (SD), minimum and maximum values of foot length and stature in both sexes and comparison between them using t- test.

\begin{tabular}{|c|c|c|c|c|c|c|}
\hline \multirow{2}{*}{ Parameters } & \multicolumn{2}{|c|}{ Mean \pm SD } & \multicolumn{2}{|c|}{ Minimum-Maximum } & \multirow{2}{*}{$\mathbf{t}$} & \multirow{2}{*}{$P$ value } \\
\hline & Male $(n=67)$ & Female $(n=53)$ & Male $(n=67)$ & Female $(n=53)$ & & \\
\hline Foot length $(\mathrm{cm})$ & $25.6 \pm 1.4$ & $23.1 \pm 0.8$ & $23.5-28.5$ & $21.9-25.1$ & 11.4 & $0.0001^{*}$ \\
\hline Stature $(\mathrm{cm})$ & $168.4 \pm 7.6$ & $161.1 \pm 5.4$ & $155.9-181.5$ & $153.5-173.6$ & 5.8 & $0.0001^{*}$ \\
\hline
\end{tabular}

* Highly significant ( $P$ is significant at $\leq 0.05$ level).

Table (2): Mean, standard deviations (SD), minimum and maximum value of foot length and stature among all subjects (number $=\mathbf{1 2 0})$.

\begin{tabular}{|l|c|c}
\hline \multicolumn{1}{|c|}{ Parameters } & Mean $\pm \mathbf{S D}$ & Minimum-Maximum \\
\hline Foot length $(\mathrm{cm})$ & $24.5 \pm 1.7$ & $21.9-28.5$ \\
\hline Stature $(\mathrm{cm})$ & $165.2 \pm 7.6$ & $153.5-181.5$ \\
\hline
\end{tabular}

Table (3): showing the sensitivity and specificity of the cut off value for foot length.

\begin{tabular}{|c|c|c|c|}
\hline Area under the curve & Best cut off value & Sensitivity & Specificity \\
\hline 0.95 & 23.95 & 96 & 81 \\
\hline
\end{tabular}

Table (4): Showing correlation coefficients between foot length and stature in males, females and all subjects.

\begin{tabular}{|l|c|c}
\hline \multirow{2}{*}{ Sex } & \multicolumn{2}{|c}{ Correlation coefficients between foot length and stature } \\
\cline { 2 - 3 } & r & p \\
\hline Males $(n=67)$ & 0.69 & $0.0001^{*}$ \\
\hline Females $(n=53)$ & 0.67 & $0.0001^{*}$ \\
\hline All subjects $(n=120)$ & 0.80 & $0.0001^{*}$ \\
\hline
\end{tabular}

(n): number of subjects, (r): Correlation coefficients

* Highly significant ( $P$ is significant at $\leq 0.05$ level).

Table (5): Regression equation for estimation of stature from foot length in males, females and all subjects.

\begin{tabular}{|l|c|c}
\hline \multicolumn{1}{|c|}{ Sex } & Regression equation for estimation of stature $=\mathrm{a}+\mathrm{bx}$ & \pm SEE \\
\hline Adult males $(n=67)$ & $71.3+3.8$ foot length & 12.5 \\
\hline Adult females $(n=53)$ & $59.4+4.4$ foot length & 15.8 \\
\hline All subjects $(n=120)$ & $82+3.4$ foot length & 6.6 \\
\hline
\end{tabular}

Regression equation for Stature $=a+b x$.

' $a$ ' is the regression coefficient of the dependent variable, i.e. stature,

' $b$ ' is the regression coefficient of the independent variable "foot length"

' $x$ ' is foot length.

SEE: the standard error of estimate

Table (6): Showing comparison of the actual stature and estimated stature from the foot length in males, females and all subjects.

\begin{tabular}{|l|l|c|c|c}
\hline \multicolumn{1}{|c|}{ Sex } & Foot length measurements (cm) & Minimal stature & Maximal stature & Mean stature \\
\hline \multirow{2}{*}{ Males $(n=67)$} & Estimated stature & 160.6 & 179.6 & 168.6 \\
\cline { 2 - 5 } & Actual stature & 155.9 & 181.5 & 168.4 \\
\hline \multirow{2}{*}{ Females $(n=53)$} & Estimated stature & 155.8 & 169.8 & 161 \\
\cline { 2 - 5 } & Actual stature & 153.5 & 173.6 & 161.1 \\
\hline \multirow{2}{*}{ All subjects $(n=120)$} & Estimated stature & 156.5 & 178.9 & 165.3 \\
\cline { 2 - 5 } & Actual stature & 153.5 & 181.5 & 165.2 \\
\hline
\end{tabular}




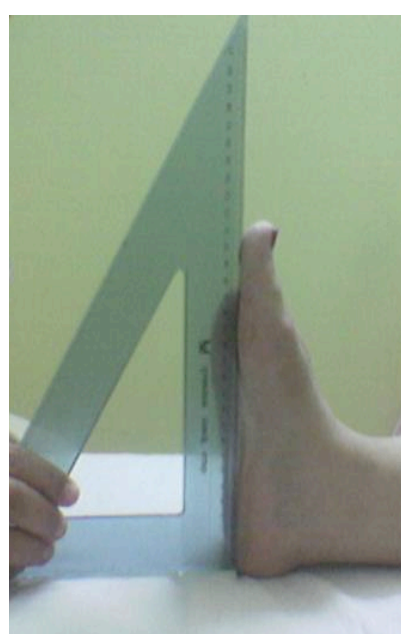

A

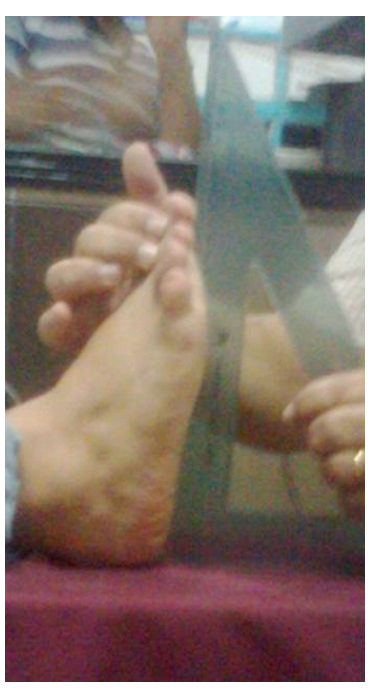

B

Figure (1): Photograph showing a measurement of foot length using right angle triangle (A: adult female 36 years, her foot length $=23 \mathrm{~cm}$; B: adult male 22 year, his foot length $=25.4 \mathrm{~cm}$ ).

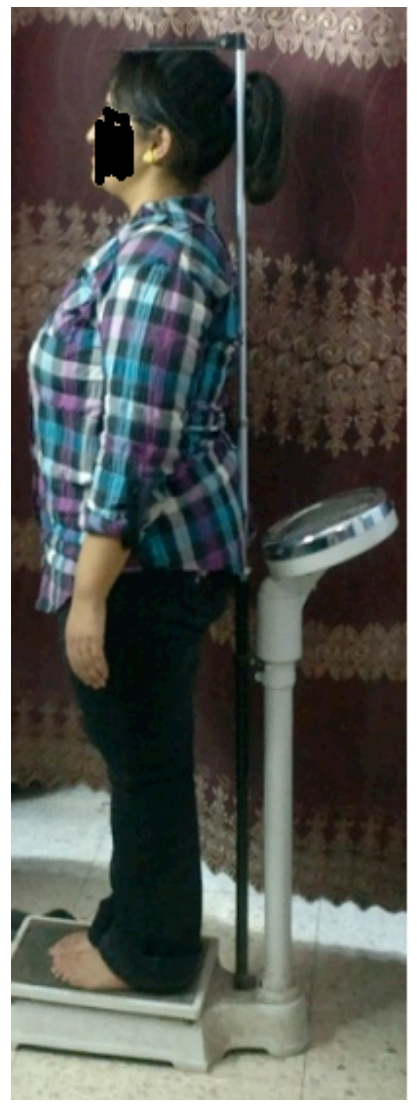

A

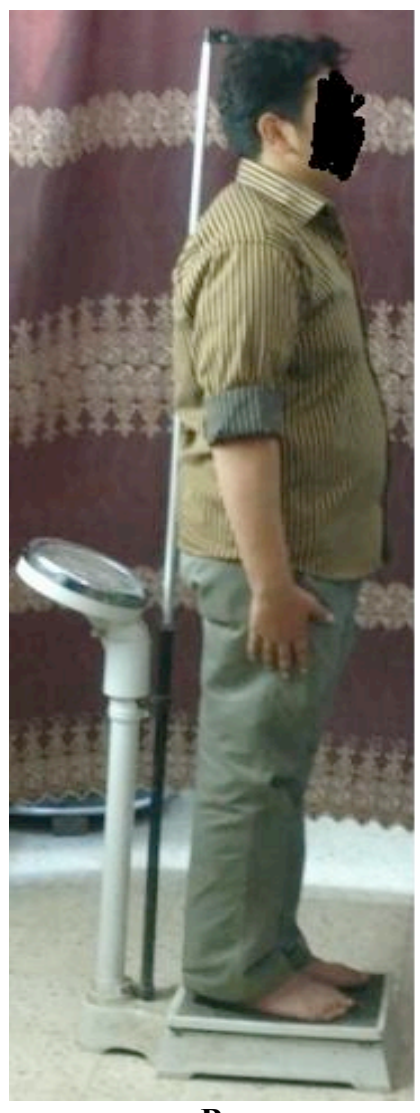

B

Figure (2): Photograph showing a measurement of stature using weight and height scales indicator \{health care provider\} (A: adult female 21 years, her stature $=153.5 \mathrm{~cm}$; B: adult male 22 years, his stature $=170.5 \mathrm{~cm}$ ). 


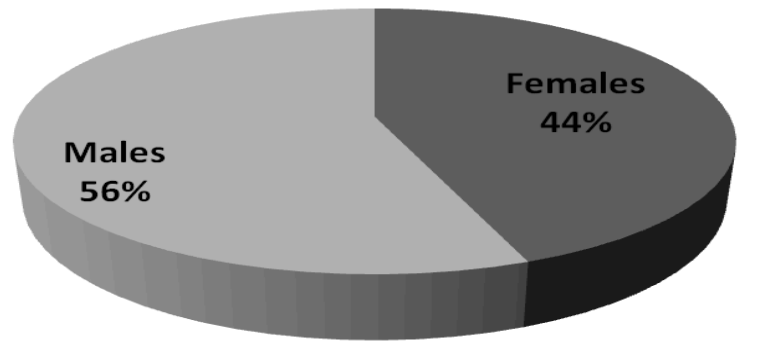

Figure (3): Pie chart shows the percentage of the participant sex.

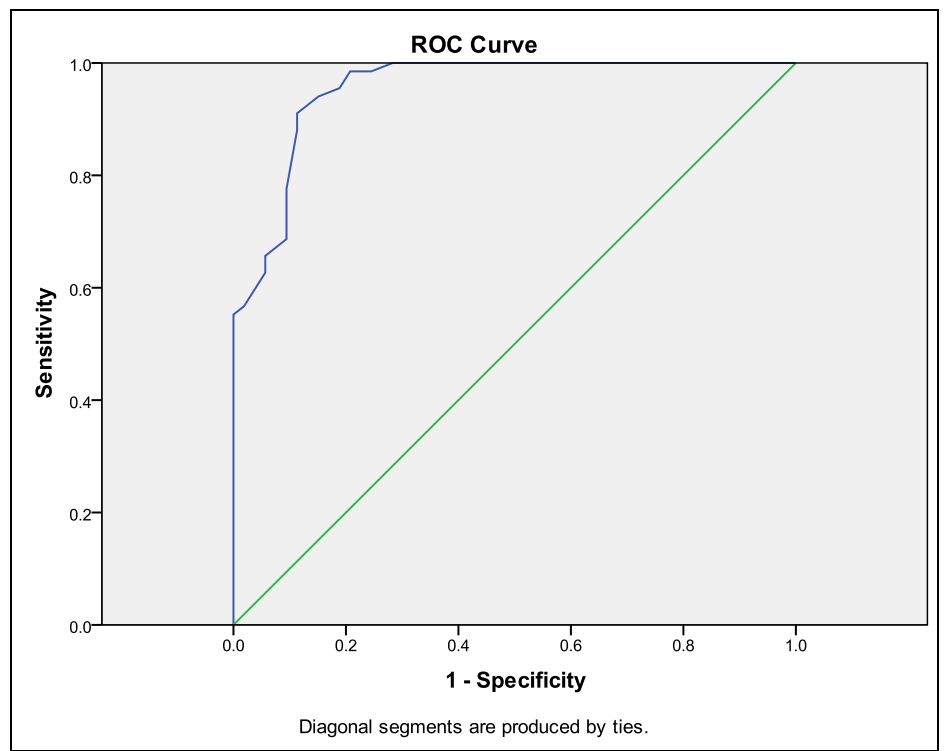

Figure (4): ROC curve was plotted to describe the sensitivity and specificity of different cut-off points. The best point lies at the elbow of the curve (its highest point to the left). ROC curve shows the performance of foot length in predicting the sex among the study group. The area under the curve (AUC) was $95 \%\{95 \%$ confidence interval 0.92- 0.98)

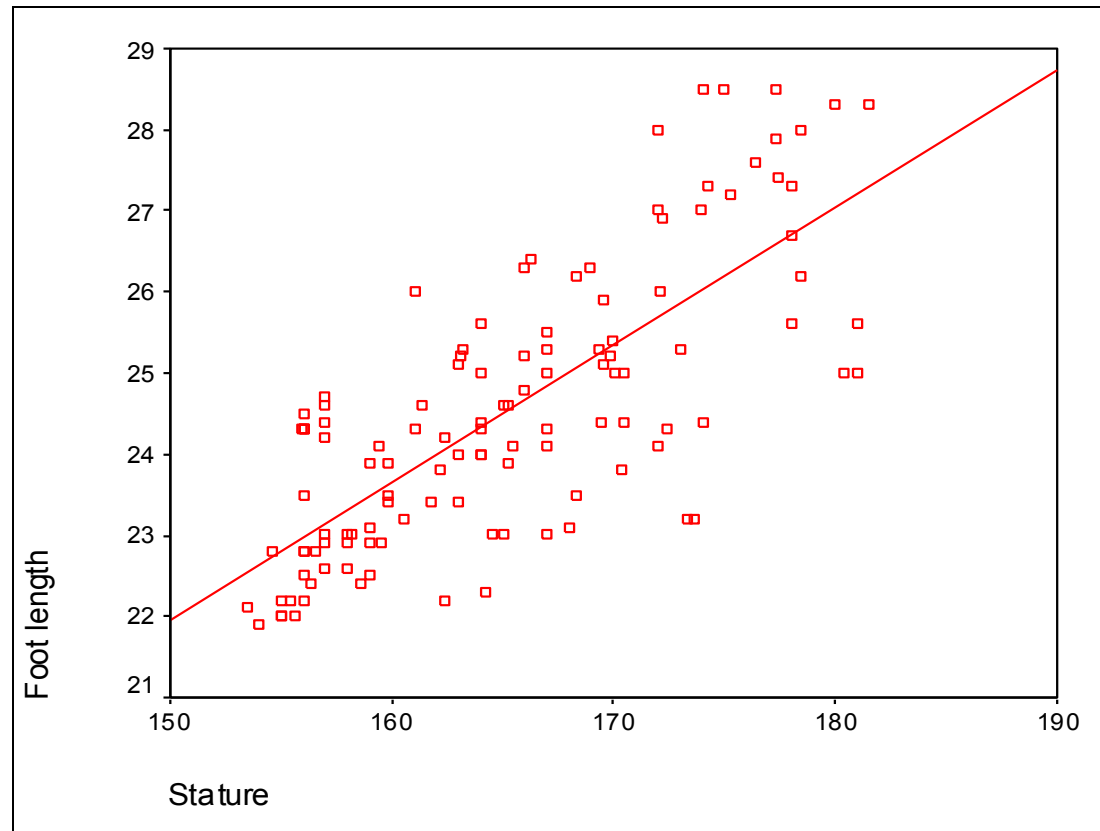

Figure (5): Showing a significant positive strong correlation between foot length and stature among all subjects $(\mathrm{r}=0.8, \mathrm{P}=0.0001$ ). $[\mathrm{r}: 0.00$ to 0.24 (weak or no correlation), 0.25 to 0.49 (fair correlation), 0.50 to 0.74 (moderate correlation), $0.75+($ strong correlation)] 


\section{Discussion}

Estimation of stature is an important tool in forensic examination. Estimation of stature becomes equally important along with other parameters like age, sex and race which considered the "big four" of forensic anthropology (Krishan, 2008). One of the objectives of the medico-legal investigation is to estimate stature or height from various skeletal remains and body parts brought for examination. Various skeletal remains and body parts bear a positive and linear correlation with stature (Krishan et al., 2012). Many studies have been conducted on the estimation of stature from various body parts like hands, trunk, intact vertebral column, upper and lower limbs, individual short and long bones, foot and footprints (Raxter et al., 2008). Numerous researches were done to develop a relationship between foot length and stature using regression models in many populations in USA, Turkey, and Native North and Central American (Daniel et al., 2005), in Mauritian people (Arun et al., 2007), in Greece (Theodoros et al., 2008) and in Indians (Deopa et al., 2010). So the aim of this study was to determine whether foot length can be used as a tool for accurate sex and stature identification among people sample from Upper Egypt or not.

The minimal age of selected subjects was 22 years with mean of $27.61 \pm 7.35$ years for males and 20 years with mean of $24.19 \pm 6.85$ years for females. These ages were chosen to ensure complete bone development as Carlyn, (2012) reported that the female bones complete their development sooner around age 18 years than those of male around age 21 years.

The present study revealed that the males had significantly $(\mathrm{P}<0.0001)$ greater mean values for foot length $(25.6 \pm 1.4)$ than females $(23.1 \pm 0.8)$ indicating the presence of significant sexual dimorphism in foot length measurements among people from Upper Egypt. Similar results were found by Danial et al., (2005) who studied 240 African-American and CaucasianAmerican US college students and proved larger proportionate foot length in males of each category compared with same-race females.

The significant differences between males and females are due to differences in body size and in muscular activity. Cortical bone in males has higher growth than in females (Black, 1978). Carlyn, (2012) reported many subtle differences between male and female skeletons. The different chromosomes in males and females result in several differences in development, most notably the hormones present in the body. Females produce a greater amount of estrogen, which in turn affects their bone development in several key ways. Males, on the other hand, produce a greater amount of testosterone which likewise affects the development of male bones. Thus, the relative size of several key features can be used to identify a male versus female skeleton. Male skeletons generally have longer, thicker bones in the arms, legs and fingers.

For all Egyptian participants, the mean and standard deviation value of foot length was $24.5 \pm 1.7$ and of stature was $165.2 \pm 7.6$. Oberoi et al., (2005) studied 100 male and 100 female college-going students of Mangalore, Karnataka and India who were 18-26 years old. The mean foot length was $23.55 \pm$ 1.61 and the mean value of stature was $163.94 \pm 9.0$. This difference can be the result of genetic factors, environmental factors affecting growth and development as nutrition, physical activity, pathological conditions, and the interaction of previous factors (Iscan and Miller, 1986).

This study found that foot length greater than 23.95 indicated males, and foot length $\leq 23.95$ indicated females with accuracy for correct sex determination of $90 \%$. This percentage exceeds that of Oberoi et al., (2005) who reported $80 \%$ accuracy of sex determination in Indians. Moreover, they found foot print length which was between 20-22.9 cm was predominated to females while the high range of foot print length which was greater than $24.6 \mathrm{~cm}$ was predominated to males.

The present study revealed that the foot length measurement shows strong positive correlation with stature $(\mathrm{r}=0.8, \mathrm{P}=0.0001)$ in all subjects (males and females). This positive correlation was moderate but slightly higher in males $(\mathrm{r}=0.69, \mathrm{P}=0.0001)$ than in females $(\mathrm{r}=0.67, \mathrm{P}=0.0001)$ which agree with some results of Oberoi et al., (2005) who found the correlation coefficient was 0.698 in males, 0.738 in females and 0.848 in the combined data. Nearby results were found in other populations as Indians (Kanchan et al., 2010a; Kanchan et al., 2010b) and in the population of North Bengal (Sen and Ghosh, 2008). Foot length was chosen for estimation of stature as foot was considered by Boonma' et al., (2010) to be a favorite bone for stature approximation. Sen and Ghosh, (2008) proved that foot length gave more accurate correlation coefficient than foot breadth in both male and female.

The study designed an equation through which stature can be calculated from foot length. This agrees with Ozden et al., (2005) who mentioned that foot dimensions could estimate the human height especially based on the foot length. Agnihotri et al., (2009) stated that determination of general demographic characteristics is the first step when confronted with unknown human skeleton identification cases. Characteristics such as age, sex, race and stature can assist to determine the boundary of possible features and provide greater chances for identification. Williams et al., (2000) proclaimed that, although many formulae for stature estimation have been proposed, their accuracy for use is population specific, as stature is influenced by race, sex and age.

The designed formula for correct stature estimation for both male and female was more or less accurate as the mean estimated stature was close to the actual stature. This was attributed to calculating the regression equations from measures of central tendency. Contrarily, Kanchan et al., (2010b) stated that some researchers derive regression formula separately for males and females. Sex, however, may not always be determined accurately, particularly in dismembered remains and thus a universal regression formula for stature estimation irrespective of sex of an 
individual is needed. In the study of Kanchan et al., (2010b) which was carried out in an endogamous group of North India to compare the accuracy of sexspecific regression models for stature estimation from foot length with the models derived when the sex was presumed as unknown. They concluded that stature can be estimated accurately from foot length by regression analysis even when sex remains unknown.

\section{Conclusion and recommendation}

It could be concluded that the foot length of Egyptians are sexually dimorphic. The foot length can to predict the sex by using the cut off value which reached by ROC to $23.95 \mathrm{~cm}$. There is strong positive correlation between foot length and stature; the stature can be calculated by using foot length through applying the regression formulae designed in this study. Its use should be applied with caution as the result had standard error of estimate (SEE) for stature estimated and only when foot completely developed. Although the foot length could be relied on to determine sex and stature accurately among Egyptians, other foot variables (such as foot width and angles) must be undertaken to reach certain detection.

\section{References}

Agnihotri AK, Kachhwaha S, Jowaheer V et al., (2009): Estimating stature from percutaneous length of tibia and ulna in Indo-Mauritian population. Forensic Science International.187:1-3.

Arun KA, Brijesh P, Kreshna G et al., (2007): Estimation of stature by foot length. Journal of Forensic and Legal Medicine. 14 (5): 279283

Auyeung TW, lee JS, Kwok T et al., (2009): Estimation of stature by measuring fibula and ulna bone length in 2443 older adults. J, Nut. Health Aging.10:931-6.

Black TK (1978): A new method for assessing the sex of fragmentary skeletal remains, femoral shaft circumference. Am. J. Phys. Anthropol.48: 227-32.

Boonma' S, RiengrojpitakS, Tiensuwarr $\mathrm{M}^{\prime}$ et al., (2010): Stature estimation from calcaneal measurements in Thai. CIFS, The $5^{\text {th }}$ academic day. 44-49.

Carlyn M (2012): The Difference between Male and Female Skeletons. At TopTenREVIEWS.com. Copyright (C) TechMediaNetwork.com.

Chibba K and Bidmos MA (2007): Using tibia fragments from South Africans of European descent to estimate maximum tibia length and stature. Forensic Science International. 169(23): 145-151.

Chiba M and Terazawa K (1998): Estimation of stature from somatometry of skull. Forensic Sci. Int. 97:87-92.

Danborno B and Elukpo A (2008): Sexual Dimorphism in Hand and Foot Length, Indices, Statureratio and Relationship to Height in Nigerians.
The Internet Journal of Forensic Science. 3 (1). DOI: $10.5580 / 379$

Daniel MT Fessler, Kevin J Haley and Roshni D LAL (2005): Sexual dimorphism in foot length proportionate to stature. Annals of Human Biology. 32(1):44-59.

Deopa D, Prakash C, Niranjan R et al., (2010): Estimation of stature from foot length in Uttarakhand region. Indian Journal of Forensic Medicine \&Toxicology.4 (1): 21 - 23.

Hong Y, Wang L, Xu DQ et al., (2011): Gender differences in foot shape: a study of Chinese young adults. Sports Biomech. 10 (2):85-97.

Iscan MY and Miller SP (1986): Sexual Dimorphism in the Femur and Tibia. In: Reichs K J, Thomas ChC. Publisher, Forensic Osteology. Advanced in the identification of Human Remains. USA, Springfield: Charles C. Thomas. pp. 101-111.

Kanchan T, Menezes RG, Lobo SW et al., (2010a): Forensic anthropology population data: Stature estimation from foot measurementsComparison of error in sex dependent and independent models. Forensic Science International.194:1-3.

KanchanT, Menezes RG, Moudgil R et al., (2010b): Stature estimation from foot length using universal regression formula in a North Indian population. Journal of Forensic Sciences. 55(1): 163-166.

Krishan K (2008): Estimation of stature from cephalofacial anthropometry in North Indian population. Forensic Sci. Int. 181(1-3):52e 16.

Krishan K, Kanchan T, Menezes RG et al., (2012): Forensic anthropology casework-essential methodological considerations in stature estimation. J Forensic Nurs. Mar; 8(1):45-50. doi: 10.1111/j.1939-3938.2011.01122.x. Epub 2012 Jan 6.

Oberoi DV, Kuruvilla A, Saralaya K et al., (2005): Estimation of stature and sex from footprint length using regression formulae and standard foot print length formula respectively. The Indian Council of Medical Research (ICMR) funded this research under Short Term Research Studentship, 2004, and the findings were presented at the XXVI National Conference of the Indian Academy of Forensic Medicine, Dehradun, India.

Ozaslan A, Koc S, Ozaslan I et al., (2006): Estimation of stature from upper extremity. Mil. Med.171; 288-291.

Ozden H, Balci Y, Demirustu C et al., (2005): Stature and sex estimate using foot and shoe dimensions. Forensic Sci Internat. 147:181-4.

Pillay VV (2004): Textbook of Forensic Medicine and Toxicology, Paras Publishing, Hyderabad, India. pp 234.

Rao NG and Kotian MS (1990): Foot print ratio- a clue for establishing sex identity. J Ind Acad Forensic Med. 12:51 -56. 
Raxter MH, Ruff CB, Azab A et al., (2008): Stature estimation in ancient Egyptians; a new technique based on anatomical reconstruction of stature. Am. J. Phys. Anthropol. 136:147155.

Robbins LM (1986): Estimating height and weight from size of foot prints. J Forensic Sci. 31:143-152.

Sen J and Ghosh S (2008): Estimation of stature from foot length and foot breadth among the Rajbanshi: An indigenous population of North Bengal. Forensic Science International. 181:13.
Theodoros BG, Constantinos M, Angeliki A et al., (2008): Correlation of foot length with height and weight in school age children. Journal of Forensic and Legal Medicine. 15 (2): 89-95.

Voracek M, Fisher ML, Rupp B et al., (2007): Sex differences in relative foot length and perceived attractiveness of female feet: relationships among anthropometry, physique, and preference ratings. Percept. Mot. Skills. 104(3 Pt 2):1123-38.

Williams PL, Bannister LH, Berry MM et al., (2000): In "Gray's Anatomy: The anatomical basis of medicine and surgery" $38^{\text {th }}$. Ed. NewYork, Churchill Livingstone.

\title{
الملخص العربي \\ هل يمكن استخذام طول القام كأداة لتحديد نوع الجلينّب وطول القامة بين عينة من البشر في
}

\author{
مـوريد مـلاك حنـاو غادة عطية اسحق 1 و إيمان سامح محمد مصطفى 2
}

الاستعر اف على نوع الجنس و تحديد طول القامة من أجزاء الجسم المختلفة يساعدإن على الإنى حل ألغاز

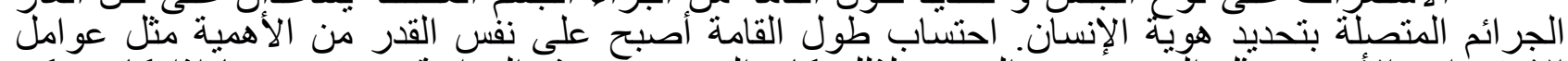

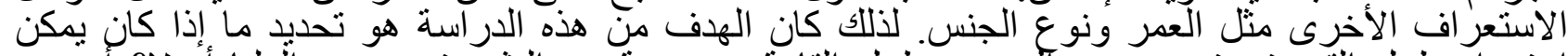

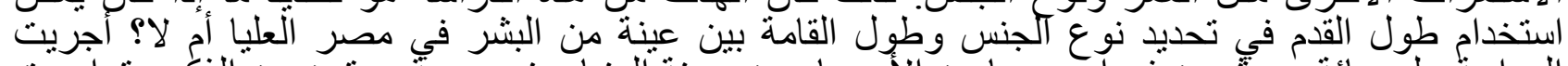

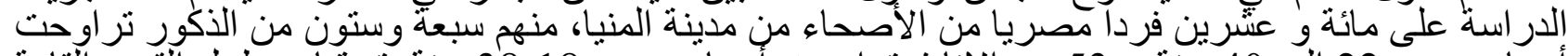

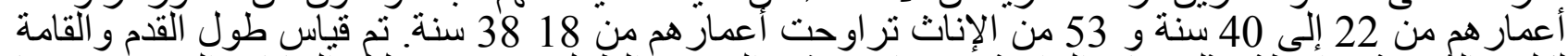

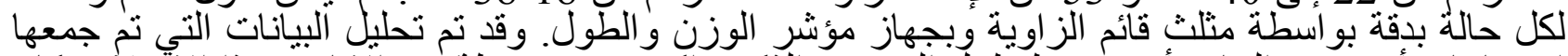

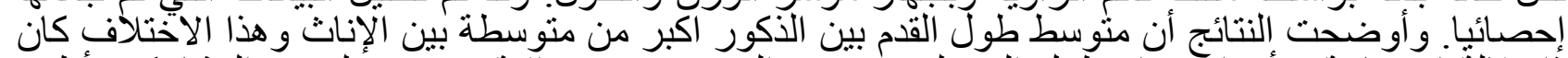

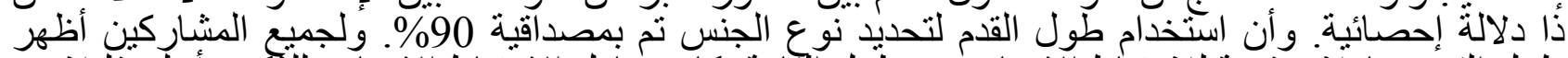

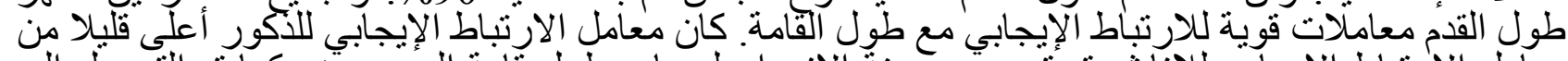

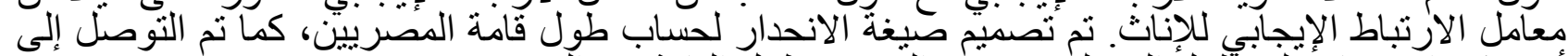

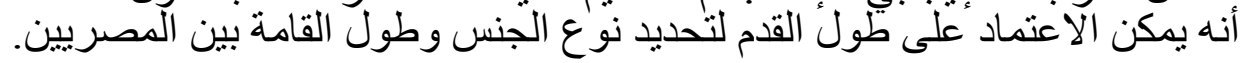

\footnotetext{
1 قسم الطب الشرعي و السموم الإكلينيكية كلية الطب جامعة المنيا

2 قسم الصحة العامة و الطب الوقائي كلية الطب جامعة المنيا
} 